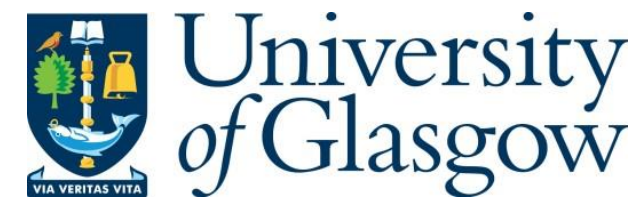

Franse, C. B., Kayigamba, F. R., Bakker, M. I., Mugisha, V., Bagiruwigize, E., Mitchell, K. , Asiimwe, A. and Schim Van Der Loeff, M. F. (2016) Linkage to HIV care before and after the introduction of provider-initiated testing and counselling in six Rwandan health facilities. AIDS Care, 29(3), pp. 326-334. (doi: 10.1080/09540121.2016.1220475)

This is the author's final accepted version.

There may be differences between this version and the published version. You are advised to consult the publisher's version if you wish to cite from it.

http://eprints.gla.ac.uk/123746/

Deposited on: 01 September 2016

Enlighten - Research publications by members of the University of Glasgow http://eprints.gla.ac.uk 


\section{Linkage to HIV care before and after the introduction of provider- initiated testing and counselling in six Rwandan health facilities}

\section{Authors:}

Carmen B FRANSE ${ }^{1}$, Felix R KAYIGAMBA ${ }^{2}$, Mirjam I BAKKER ${ }^{1}$, Veronicah

MUGISHA $^{3}$, Emmanuel BAGIRUWIGIZE ${ }^{4}$, Kirstin R MITCHELL ${ }^{5}$, Anita

ASIIMWE ${ }^{6}$, Maarten F SCHIM VAN DER LOEFF ${ }^{7,8,9^{*}}$

\section{Affiliations:}

1- Royal Tropical Institute, KIT Biomedical Research, Amsterdam, The Netherlands

2- INTERACT, Kigali, Rwanda

3- ICAP, Mailman School of Public Health, Columbia University, Kigali, Rwanda

4- Ruhengeri hospital, Musanze, Rwanda

5- London School of Hygiene and Tropical Medicine, London, UK

6- University of Rwanda, Kigali, Rwanda

7- Amsterdam Institute of Global Health and Development (AIGHD), Amsterdam, the Netherlands

8- Center for Infection and Immunity Amsterdam (CINIMA), AMC, Amsterdam, the Netherlands

9- Public Health Service of Amsterdam (GGD), Amsterdam, the Netherlands

*Corresponding author, email address: mschimvdloeff@ggd.amsterdam.nl

\section{Acknowledgements}

We would like to thank all study participants, INTERACT staff, clinic staff of participating health facilities and community workers. We thank Frank Cobelens for his feedback on a draft of this manuscript. This work was supported by The Netherlands Organization for Scientific Research/Netherlands Foundation for the Advancement of Tropical Research (NWO-WOTRO/NACCAP) under Grant: W070520100; and the European Union under Grant: SANTE/2006/105-316. 
MSVDL, MB, FK, designed the study and AA, EB, VM advised on the study concept and design. FK, EB, CF led the data collection and all authors advised on data collection. CF did the main quantitative and qualitative analyses, MSVDL advised on quantitative analysis and KM on qualitative design and analysis. All authors contributed to the interpretation of findings. CF wrote the first draft of the manuscript, all authors made critical revisions and all approved the final version. 


\section{Linkage to HIV care before and after the introduction of provider-initiated testing and counselling in six Rwandan health facilities}

\section{Abstract}

HIV testing and counselling forms the gateway to the HIV care and treatment continuum.

Therefore, the World Health Organization recommends provider-initiated testing and counselling (PITC) in countries with a generalized HIV epidemic. Few studies have investigated linkage-to-HIV-care among out-patients after PITC. Our objective was to study timely linkageto-HIV-care in six Rwandan health facilities before and after the introduction of PITC in the out-patient departments (OPDs). Information from patients diagnosed with HIV was abstracted from VCT, OPD and laboratory registers of six Rwandan health facilities during 3-month periods before (March-May 2009) and after (December 2009-February 2010) the introduction of PITC in the OPDs of these facilities. Information on patients' subsequent linkage-to-preantiretroviral treatment (ART) care and ART was abstracted from ART clinic registers of each health facility. To triangulate the findings from health facility routine, a survey was held among patients to assess reasons for non-enrolment. Of 635 patients with an HIV diagnosis, 232 (36.5\%) enrolled at the ART clinic within 90 days of diagnosis. Enrolment among out-patients decreased after the introduction of PITC, (adjusted odds ratio, 2.0; 95\% confidence interval, 1.04.2; $\mathrm{p}=0.051$ ). Survey findings showed that retesting for HIV among patients already diagnosed and enrolled into care was not uncommon. Patients reported non-acceptance of disease status, stigma, and problems with healthcare services as main barriers for enrolment. Timely linkageto-HIV-care was suboptimal in this Rwandan study before and after the introduction of PITC; the introduction of PITC in the OPD may have had a negative impact on linkage-to-HIV-care. Healthier patients tested through PITC might be less ready to engage in HIV care. Fear of HIV stigma and mistrust of test results appear to be at the root of these problems.

Key words: HIV, Continuity of Patient Care, Antiretroviral therapy, Mass Screening, Africa South of the Sahara, Rwanda. 


\section{Introduction}

The increase in access to antiretroviral therapy (ART) in sub-Sahara Africa (SSA) is a success story in the history of the HIV epidemic (World Health Organization (WHO), 2013). ART has proven effective in reducing mortality rates among people infected with HIV (Palella et al., 1998), as well as reducing vertical (De Cock et al., 2000; Siegfried et al., 2011) and horizontal transmission rates (Cohen et al., 2011). Therefore, WHO recommends provider-initiated testing and counselling (PITC) in countries with an HIV prevalence of $3.0 \%$ or higher (WHO, 2007). HIV testing and counselling forms the gateway to the care and treatment continuum (McNairy \& El Sadr, 2012). However, only one-third to two-thirds of patients with a new HIV diagnosis are tested for CD4 or return for results within 3 months of the HIV test in SSA (Kranzer et al., 2012; Rosen \& Fox, 2011). Transport costs and distance to clinic, as well as stigma and fear of disclosure are common barriers towards linkage-to-HIV-care (Govindasamy et al., 2012; Lankowski et al., 2014).

Rwanda is a densely populated country, with an adult HIV seroprevalence rate of $3.0 \%$ (National Institute of Statistics of Rwanda (NISR), 2012). The prevalence is higher in urban $(7.1 \%)$ than rural areas $(2.3 \%)$ (NISR, 2012). ART is available in $93 \%$ of hospitals and 29\% of health centres (HC) (NISR, 2008). In 2005, the Demographic and Health survey of Rwanda reported that around $80 \%$ of adults had not been tested for HIV (NISR, 2006). The Ministry of Health (MOH) therefore recommended introducing PITC in all its health facilities (HFs) in 2008. At the start of the study, PITC was already running with high uptake rates among antenatal women and tuberculosis (TB) patients. PITC was not practiced in out-patient departments (OPDs); HIV testing was only performed when out-patients presented with symptoms of HIV infection. 
PITC has increased ART uptake in antenatal care (ANC) clinics in SSA (Hensen et al., 2012). Fewer studies have investigated linkage-to-HIV-care among out-patients after PITC (Kennedy et al., 2013; Roura et al., 2013). In this study a PITC intervention was introduced in OPDs of six Rwandan HFs. The objective of this study was to examine linkage-to-HIV-care (pre-ART, eligibility for ART and start of ART) before and after the introduction of a PITC intervention in the OPD. As patients who attend the OPD for a purpose other than getting an HIV test might be less motivated to seek HIV care than patients specifically coming for HIV testing, we hypothesized that linkage-to-HIV-care at the OPD would be lower after the introduction of PITC. 


\section{Methods}

\section{Setting}

The current study was part of a cluster non-randomized controlled trial that investigated the HIV testing uptake and acceptability of introducing a PITC intervention in OPDs of Rwandan HFs (Kayigamba et al., 2012; Kayigamba et al., 2014). Eight Rwandan HFs were purposefully selected for this trial, ensuring inclusion of urban and rural HFs and sufficient numbers of attendees. All these HFs had a complete range of HIV testing, care and treatment activities in place. All HFs had an OPD, where routine PITC was not yet practiced at the start of the study. HFs were located in the Musanze district in the North-West of Rwanda (Ruhengeri hospital, Muhoza HC, Rwaza HC and control site Gasiza HC) and in the Gasabo district surrounding the capital Kigali (Kibagabaga hospital, Kimironko HC, Kinyinya HC and control site Kabuye HC).

This study investigated linkage-to-HIV-care before and after the introduction of a PITC intervention. The following stages were investigated: (1) Linkage-to-pre-ART-care (we studied how many patients registered at the HFs ART clinic within 90 days of HIV diagnosis); (2) Eligibility for ART (at the time of the study, HIV infected patients were eligible for ART when CD4 count was $<350$ cells $/ \mathrm{mm}^{3}$ or they were in WHO clinical stage 4; TB was classified as WHO stage 3 (Trac-plus, 2009)); (3) Start of ART (we studied how many eligible patients started ART within 90 days of HIV diagnosis). This study is a sub analysis of data from the OPDs and voluntary counselling and testing (VCT) departments of the six HFs that implemented the intervention. Data from VCTdepartments were included in order to examine whether linkage-to-HIV-care among out-patients differed from VCT-patients and to detect seasonal effects. Due to low 
numbers of HIV cases in the two control HFs, these could not serve as control sites for the purpose of the current study and were therefore excluded (Kayigamba et al., 2012). Characteristics of the HFs included in this study are described in Table S1.

\section{The intervention}

The intervention consisted of three phases: in phase 1 (March-May 2009) PITC was not operational in OPDs. In phase 2 (June-November 2009) healthcare workers (HCW) were trained to offer PITC and provided materials, administer HIV testing, and use registers adapted for the study to record details of testing. In phase 3 (December 2009 February 2010) PITC was fully operational in the OPDs. Patients in OPDs were systematically offered an HIV test on an opt-out basis. We anticipated that this new intervention would increase workload and responsibility for $\mathrm{HCW}$; accordingly we provided salary top-ups to department heads and stipends to HCW.

\section{Data collection}

At each HF, patients who were diagnosed with HIV were referred to the ART clinic of that HF, with the exception of one clinic (Muhoza), from where patients were referred to the neighbouring Ruhengeri hospital. At the ART clinic each patient was examined by a physician, the WHO stage was established, and a blood sample was taken to measure the CD4 count. Information on patients' subsequent linkage-to-pre-ART care and ART was abstracted from ART clinic registers of each HF. Information from patients diagnosed with HIV was abstracted from VCT, OPD and laboratory registers of six Rwandan HFs during 3-month periods before (March-May 2009) and after (December 2009-February 2010) the introduction of PITC in the OPDs of these HFs. 
Data collection and hospital routine have been described in detail before (Kayigamba et al., 2012).

\section{Survey}

We conducted a survey in order to identify patient-reported barriers towards linkage-toHIV-care. We interviewed a convenience sample of patients from each HF aged 18 years or above who were diagnosed with HIV in phase 3 and did not enrol within 90 days. The survey was done in August 2010 at patients' homes. For this survey, a questionnaire was developed that included closed questions on demographic characteristics of the patient, whether the patient enrolled into care at the time of the survey and, if so, into which HF, and a final open-ended question about his/her reason(s) for not enrolling into HIV care. The questions were read to patients in Kinyarwanda by trained interviewers. Answers were written down on the questionnaire form and later translated into English by a trained translator.

\section{Data analysis}

We used STATA software release 11 (StataCorp, College Station, TX, USA) for all quantitative analyses. Associations between four explanatory variables (department by phase, site, sex and age) and five outcomes (enrolment into pre-ART care; advanced WHO stage; CD4 count; ART eligibility; and start of ART) were assessed using the chisquared test, Fisher's exact test or Kruskal-Wallis test, as appropriate. Multivariable logistic regression analyses were done to identify factors associated with non-enrolment into pre-ART care, advanced clinical disease stage (WHO stage 3 or 4), ART eligibility and not starting ART. All explanatory variables were included in multivariable models a priori. $\mathrm{P}$ values of $<0.05$ were considered statistically significant. Time from HIV 
diagnosis to enrolment into pre-ART care and to start of ART, and time from CD4 count to start of ART were examined with Kaplan-Meier graphs.

Answers to the open-ended survey question regarding reasons for non-enrolment in preART care were read multiple times and coded by a researcher $[\mathrm{CF}]$ using principles of thematic analysis (Boyatzis, 1998). When concepts or statements were unclear, the meaning of words in Kinyarwanda was discussed with the translator. Codes were categorized into overarching themes by discussing the findings among the authors $[\mathrm{CF}$, $\mathrm{KM}, \mathrm{MB}$ and $\mathrm{FK}]$ and reviewing the existing literature on commonly reported barriers towards linkage-to-HIV-care.

\section{Ethics}

Ethical approval was provided by the Rwandan National Ethics Committee and the research ethics committee of the Academic Medical Center, Amsterdam. Permission for home visits and written informed consent was obtained from all patients. 


\section{Results}

\section{Patients diagnosed with HIV}

In phases 1 and 3 of the study, 722 patients were diagnosed with HIV; children below 15 years $(n=23)$ were excluded, as were 64 patients due to missing names or codes (Figure 1), leaving 635 patients in the analysis.

Most patients were female $(61.7 \%)$ and the median age was 30 years (interquartile range [IQR] 24-38). In phase 1, 73 patients (23.5\%) were diagnosed at the OPD. In phase 3, the number and the relative share of patients diagnosed at the OPD increased (125; $38.5 \%$ ). Between 13 to 255 persons were diagnosed at each individual site.

\section{Linkage-to-pre-ART-care}

Among the 635 patients, 232 (36.5\%) enrolled into pre-ART care during phase 1 and 3 combined (Figure 1). There was no significant difference in enrolment by sex or age (Table 1), but enrolment varied strongly by study site: Muhoza had the lowest enrolment (23.5\%), and Rwaza the highest (55.6\%; p<0.001). Among VCT-patients enrolment remained relatively constant during phase 1 and 3 (38.3\% and 35.5\% respectively). Enrolment among out-patients was slightly higher than among VCTpatients during phase 1 (43.8\%), but enrolment among out-patients was lower during phase $3(29.6 \%)$. The difference between enrolment among out-patients in phase 1 and 3 was significant in univariable, but not in multivariable analysis (adjusted odds ratio $[\mathrm{aOR}], 2.0 ; 95 \%$ confidence interval $[\mathrm{CI}], 1.0-4.2 ; \mathrm{p}=0.051$, Table 2).

Of the 232 patients enrolled into pre-ART care, 169 (74.6\%) had done so 14 days after HIV diagnosis, and 205 (88.4\%) after 30 days (Figure 2a). Among those who enrolled, 
the median time to enrolment was 6 days (IQR 2-15). Median time to enrolment in phase 1 was 3.5 days (IQR 1-13.5) among VCT-patients, and 9 days (IQR 4.5-20.5) among out-patients. This was similar in phase 3 (4 days [IQR 2-10] and 9 days [IQR 419] respectively).

\section{ART eligibility}

Of the 232 patients enrolled in pre-ART care, WHO staging was available for 217 (93.5\%) of patients. Of these, $19.8 \%$ were in WHO stage 3 and none were in stage 4 (Table 1). This was similar for men and women (20.9\% and $19.1 \%$ respectively). Only study site was significantly associated with high WHO stage in univariable and multivariable analysis (Table S2).

CD4 count was available for 218 patients (94.0\%). Median CD4 count was 384 cells $/ \mathrm{mm}^{3}$ (IQR, 214-539; Table 1). CD4 counts were significantly lower among men and older patients $(\mathrm{p}=0.003$ and $\mathrm{p}=0.011$ respectively). Among out-patients, the median CD4 count was 287 cells $/ \mathrm{mm}^{3}$ in phase 1 and 312 cells $/ \mathrm{mm}^{3}$ in phase 3 and among VCT-patients, the median CD4 count was 398 cells $/ \mathrm{mm}^{3}$ in phase 1 and 431 cells $/ \mathrm{mm}^{3}$ in phase $3(\mathrm{p}=0.008)$. CD4 counts did not differ significantly between sites (Table 1).

Both CD4 count and WHO staging was available for $89.7 \%(208 / 232)$ of patients. Of these, $93(44.7 \%)$ were eligible for ART (Table 1). ART eligibility was fully dependent on a low CD4 count $\left(<350\right.$ cells $\left./ \mathrm{mm}^{3}\right)$ as none of the patients were classified in WHO stage 4. Only sex was significantly associated with ART eligibility $(\mathrm{p}=0.017)$, with men being more often eligible for ART than women (aOR 1.9; 95\% CI 1.0-3.5; Table S3).

\section{Start of ART}


Of the 93 patients eligible for ART, 48 (51.6\%) started ART within 90 days of HIV diagnosis (Figure 1). Among the 48 patients who started ART the median time between HIV diagnosis and start of ART was 35.5 days (IQR, 17-60), and between CD4 count and start of ART 27 days (IQR, 12.5-50) (Figure 2b\&2c). The proportions of patients starting ART varied significantly by study site (Table 1; Table S4). Due to small numbers, we did not perform multivariable analysis.

\section{Survey results}

In total, 60 patients (34 VCT-patients and 26 out-patients) -who had not been enrolled into pre-ART care in phase 3 of the study- were interviewed for the survey (76\% of the approached patients). Main reason for non-interview was that the patient had moved or could not be found at the provided address at the time of interview.

The majority of patients 57\% (34/60) were still not enrolled into pre-ART care (Table $3)$. Of the patients who did enrol, most $(10 / 60,17 \%)$ enrolled at a different HF then the one they were tested at, and only 2/60 (3\%) enrolled at the same HF. A large proportion of patients $(14 / 60,23 \%)$ were already enrolled into pre-ART care before they took an HIV test (a retest) in phase 3. Among VCT-patients $29 \%(10 / 34)$ had retested for HIV and among out-patients 15\% (4/26) had retested for HIV (Table 3). VCT-patients had retested for HIV on their own initiative. Some patients that were already taking ART mentioned taking a retest to assess whether they had been cured by prayers. Out-patients had been retested on request by the HCW at the OPD.

A reason for not enrolling into HIV care that was often reported was not accepting or mistrusting one's positive HIV status $(7 / 34,21 \%)$. Some patients mentioned taking up to three or four tests at different facilities to confirm the results. Patients often reported 
that they did not want to return to the same clinic after an HIV diagnosis, because of fear of being seen and stigmatized by people they knew $(8 / 34,24 \%)$. Some of the patients that reported this reason had enrolled at a different HF. Many patients (8/34, $24 \%$ ) reported that they did not enrol into HIV care because they encountered problems at the HF (Table 3). Specific reasons given were: long waiting times, not being told, or not realising, that they had to return for a follow-up, or failing to find the HCW at the given follow-up appointment. Some patients $(5 / 34,15 \%)$ mentioned that after an initial positive result they were tested at a different HF and had a negative HIV outcome there. 


\section{Discussion}

In this study in six Rwandan HFs, timely linkage-to-pre-ART-care and ART was suboptimal before and after the introduction of PITC. We found that enrolment among out-patients was lower after the implementation of PITC, although this finding was not significant in multivariable analysis.

It is possible that under PITC, healthier out-patients enrolled less often. As hypothesized, when coming to the OPD for a different reason than to be tested for HIV, some patients might be less ready to enrol into HIV care; this may be especially the case for patients without clear symptoms of HIV. Low perceived susceptibility to HIV has been linked to treatment avoidance (Varni et al., 2012; Nakigozi et al., 2013). This hypothesis is supported by the finding that out-patients in this study that enrolled into pre-ART care had lower absolute CD4 counts than VCT-patients both before and after the introduction of PITC. Several studies report that operational problems such as increased waiting times are common under PITC (Roura et al., 2013; Topp et al., 2010; Evans \& Ndirangu, 2009). This could also have led to lower linkage-to-pre-ART-care after PITC in this study. Problems with health services were one of the main barriers towards linkage-to-care reported by patients in this study. Higher workload and longer consultation time under PITC were reported by heath staff, as previously discussed (Kayigamba et al., 2014).

However, our findings should be interpreted with caution. The proportion of patients enrolling into pre-ART care in this study, both at the VCT and OPD department before as well as after the introduction of PITC, was among the lowest reported in SSA 
(Kranzer et al., 2012; Rosen \& Fox, 2011; Mutimura et al., 2014). Our survey among patients that were not registered at the ART clinic demonstrated that this proportion was an underestimate of patients actually linked to pre-ART care. This survey showed that over one-third of these non-registered patients had in fact enrolled at a different HF or, perhaps surprisingly, had already enrolled in HIV care prior to their diagnosis in this study. It is likely that these factors may have also led to underestimates of patients linking to pre-ART care in other studies from SSA, as in many places no tracking system is operational to track patients after an HIV diagnosis (Rosen \& Fox, 2011; Bassett et al., 2010).

Retesting for HIV appears to happen frequently, among non-enrolled patients and patients already enrolled into HIV care. Under PITC a previous HIV diagnosis and enrolment in care might not be communicated to the HCW. Different research by our group (Kayigamba et al., 2012; Kayigamba et al., 2014) found that before the introduction of PITC the most common reason for testing was the desire to know one's HIV status, while afterwards this was because one was offered a test. Some patients reported an HIV negative test after their initial positive test when they were tested at a different facility. False positive rapid-test results have been reported in the literature (Gray et al., 2007; Anzala et al., 2008; Kagulire et al., 2011; Klarkowski et al., 2009), but operational issues, such as non-observance of standard operating procedures and lack of quality control might also play a role (Shanks et al., 2013).

Our findings should be viewed in the wider context of a strong present HIV/AIDS stigma. Difficulty in accepting their test result and fear of being seen at the HF were 
main barriers towards enrolment in pre-ART care mentioned by patients in this study and also resulted in them repeating HIV testing. Other studies have reported that denial of HIV status and fear of HIV stigma can result in non-engagement in care and decreased quality of life (Kamen et al., 2012; Weaver et al., 2004; Nakigozi et al., 2013; Beer et al., 2009).

This study was subject to certain limitations. Missing or non-matching data between HF registers (names, age, sex, initial department of consultation) resulted in the exclusion of $9 \%$ of patients. The survey was held among a relatively small sample of patients from phase 3. We were unable to explore differences in reported barriers before and after the introduction of PITC and the power to find significant differences between VCT and OPD departments was limited. A key strength of our study is that we used routine data from primary care clinics and hospitals, reflecting routine healthcare practice. Another strength is that we triangulated our findings from the hospital registers with data from a survey among non-enrolled patients, through which we were able to explore patientreported barriers towards linkage-to-HIV-care.

In conclusion, the introduction of PITC in the OPD may have had a negative impact on linkage-to-HIV-care in Rwandan HFs. Healthier patients tested through PITC might be less ready to engage in HIV care. Fear of HIV stigma and mistrust of test results appear to be at the root of these problems. 


\section{Captions}

Figure 1. Flow of linkage-to-pre-ART-care and start of ART among HIV infected patients, Rwanda, March - May 2009 (phase 1) and December 2009 - February 2010 (phase 3).

$\mathrm{ART}=$ antiretroviral treatment; $\mathrm{WHO}=$ World Health Organization.

Figure 2. a. Time to enrolment at ART clinic among 635 HIV patients from date of HIV diagnosis. b. Time to start ART among 93 eligible HIV patients, from date of HIV diagnosis. c. Time to start ART among 93 eligible HIV patients, from date of CD4 count. Rwanda, March - May 2009 (phase 1) and December 2009 - February 2010 (phase 3). 


\section{References}

Anzala, O., Sanders, E. J., Kamali, A., Katende, M., Mutua, G. N., Ruzagira, E. et al. (2008). Sensitivity and specificity of HIV rapid tests used for research and voluntary counselling and testing. East Afr.Med.J., 85, 500-504.

Bassett, I. V., Regan, S., Chetty, S., Giddy, J., Uhler, L. M., Holst, H. et al. (2010). Who starts antiretroviral therapy in Durban, South Africa?... not everyone who should. AIDS, 24 Suppl 1, S37-S44.

Beer, L., Fagan, J. L., Valverde, E., \& Bertolli, J. (2009). Health-related beliefs and decisions about accessing HIV medical care among HIV-infected persons who are not receiving care. AIDS Patient Care STDS, 23, 785-792.

Boyatzis, R. (1998). Transforming qualitative information: Thematic analysis and code development.Thousand Oaks: SAGE Publications.

Cohen, M. S., Chen, Y. Q., McCauley, M., Gamble, T., Hosseinipour, M. C., Kumarasamy, N. et al. (2011). Prevention of HIV-1 infection with early antiretroviral therapy. $N$ Engl J Med, 365, 493-505.

De Cock, K. M., Fowler, M. G., Mercier, E., de Vincenzi, I., Saba, J., Hoff, E. et al. (2000). Prevention of mother-to-child HIV transmission in resource-poor countries: translating research into policy and practice. JAMA, 283, 1175-1182.

Evans, C. \& Ndirangu, E. (2009). The nursing implications of routine provider-initiated HIV testing and counselling in sub-Saharan Africa: a critical review of new policy guidance from WHO/UNAIDS. Int.J.Nurs.Stud., 46, 723-731. 
Govindasamy, D., Ford, N., \& Kranzer, K. (2012). Risk factors, barriers and facilitators for linkage to antiretroviral therapy care: a systematic review. AIDS, 26, 20592067.

Gray, R. H., Makumbi, F., Serwadda, D., Lutalo, T., Nalugoda, F., Opendi, P. et al. (2007). Limitations of rapid HIV-1 tests during screening for trials in Uganda: diagnostic test accuracy study. BMJ, 335, 188.

Hensen, B., Baggaley, R., Wong, V. J., Grabbe, K. L., Shaffer, N., Lo, Y. R. J. et al. (2012). Universal voluntary HIV testing in antenatal care settings: a review of the contribution of provider-initiated testing \& counselling. Trop.Med.Int.Health, 17, 59-70.

Kagulire, S. C., Opendi, P., Stamper, P. D., Nakavuma, J. L., Mills, L. A., Makumbi, F. et al. (2011). Field evaluation of five rapid diagnostic tests for screening of HIV1 infections in rural Rakai, Uganda. Int.J.STD AIDS, 22, 308-309.

Kamen, C., Taniguchi, S., Student, A., Kienitz, E., Giles, K., Khan, C. et al. (2012). The impact of denial on health-related quality of life in patients with HIV. Qual.Life Res., 21, 1327-1336.

Kayigamba, F. R., Bakker, M. I., Fikse, H., Mugisha, V., Asiimwe, A., \& Schim van der Loeff, M. (2012). Patient enrolment into HIV care and treatment within 90 days of HIV diagnosis in eight Rwandan health facilities: a review of facilitybased registers. PLoS One, 7, e36792.

Kayigamba, F. R., Bakker, M. I., Lammers, J., Mugisha, V., Bagiruwigize, E., Asiimwe, A. et al. (2014). Provider-initiated HIV testing and counselling in 
Rwanda: acceptability among clinic attendees and workers, reasons for testing and predictors of testing. PLoS One, 9, e95459.

Kennedy, C. E., Fonner, V. A., Sweat, M. D., Okero, F. A., Baggaley, R., \& O'Reilly, K. R. (2013). Provider-initiated HIV testing and counseling in low- and middleincome countries: a systematic review. AIDS Behav., 17, 1571-1590.

Klarkowski, D. B., Wazome, J. M., Lokuge, K. M., Shanks, L., Mills, C. F., \& O'Brien, D. P. (2009). The evaluation of a rapid in situ HIV confirmation test in a programme with a high failure rate of the WHO HIV two-test diagnostic algorithm. PLoS One, 4, e4351.

Kranzer, K., Govindasamy, D., Ford, N., Johnston, V., \& Lawn, S. D. (2012).

Quantifying and addressing losses along the continuum of care for people living with HIV infection in sub-Saharan Africa: a systematic review. J.Int.AIDS Soc., $15,17383$.

Lankowski, A. J., Siedner, M. J., Bangsberg, D. R., \& Tsai, A. C. (2014). Impact of geographic and transportation-related barriers on HIV outcomes in sub-Saharan Africa: a systematic review. AIDS Behav., 18, 1199-1223.

McNairy, M. L. \& El Sadr, W. M. (2012). The HIV care continuum: no partial credit given. AIDS, 26, 1735-1738.

Mutimura, E., Addison, D., Anastos, K., Hoover, D., Dusingize, J., Karenzi, B. et al. (2014). Trends in and determinants of CD4+ cell count at antiretroviral therapy initiation after changes in national ART guidelines in Rwanda. AIDS, 29(1), 6776. 
Nakigozi, G., Atuyambe, L., Kamya, M., Makumbi, F. E., Chang, L. W., Nakyanjo, N. et al. (2013). A Qualitative Study of Barriers to Enrollment into Free HIV Care: Perspectives of Never-in-Care HIV-Positive Patients and Providers in Rakai, Uganda. Biomed.Res.Int., vol. 2013, ID 470245.

National Institute of Statistics of Rwanda (NISR) (2006). Rwanda Demographic and Health Survey 2005 Calverton, Maryland, U.S.A: INSR and ORC Macro.

National Institute of Statistics of Rwanda (NISR) (2008). Rwanda Service Provision Assessment Survey 2007 Calverton, Maryland, U.S.A.: NIS, MOH, and Macro International Inc.

National Institute of Statistics of Rwanda (NISR) (2012). Rwanda Demographic and Health Survey 2010 Calverton, Maryland, USA: NISR, MOH, and ICF International.

Palella, F. J. J., Delaney, K. M., Moorman, A. C., Loveless, M. O., Fuhrer, J., Satten, G. A. et al. (1998). Declining morbidity and mortality among patients with advanced human immunodeficiency virus infection. HIV Outpatient Study Investigators. N.Engl.J.Med., 338, 853-860.

Rosen, S. \& Fox, M. P. (2011). Retention in HIV care between testing and treatment in sub-Saharan Africa: a systematic review. PLoS Med, 8, e1001056.

Roura, M., Watson-Jones, D., Kahawita, T. M., Ferguson, L., \& Ross, D. A. (2013). Provider-initiated testing and counselling programmes in sub-Saharan Africa: a systematic review of their operational implementation. AIDS, 27, 617-626. 
Shanks, L., Klarkowski, D., \& O'Brien, D. P. (2013). False positive HIV diagnoses in resource limited settings: operational lessons learned for HIV programmes. PLoS One, 8, e59906.

Siegfried, N., van der Merwe, L., Brocklehurst, P., \& Sint, T. T. (2011). Antiretrovirals for reducing the risk of mother-to-child transmission of HIV infection. Cochrane Database Syst. Rev., CD003510.

Topp, S. M., Chipukuma, J. M., Giganti, M., Mwango, L. K., Chiko, L. M., Tambatamba-Chapula, B. et al. (2010). Strengthening health systems at facilitylevel: feasibility of integrating antiretroviral therapy into primary health care services in lusaka, zambia. PLoS One, 5, e11522.

Trac-plus (2009). Guidelines for the provision of comprehensive care to persons infected by HIV in Rwanda. Kigali, Rwanda.

Varni, S., Miller, C., McCuin, T., \& Solomon, S. (2012). Disengagement and Engagement Coping with HIV/AIDS Stigma and Psychological Well-Being of People with HIV/AIDS. J.Soc.Clin.Psychol., 31, 123-150.

Weaver, K. E., Antoni, M. H., Lechner, S. C., Duran, R. E. F., Penedo, F., Fernandez, M. I. et al. (2004). Perceived stress mediates the effects of coping on the quality of life of HIV-positive women on highly active antiretroviral therapy. AIDS Behav., 8, 175-183.

World Health Organization (WHO) (2007). Guidance on provider-initiated HIV testing and counselling in health facilities. Strengthening health services to fight HIV/AIDS. Geneva: WHO. 
World Health Organization (WHO) (2013). Global report on HIV treatment 2013:

results, impact and opportunities. Geneva: WHO. 
Table 1: Linkage to pre-ART care, WHO stage, CD4 count, ART eligibility, and start of ART, by department of test, study phase, study site, sex and age; Rwanda, March - May 2009 (phase 1) and December 2009 - February 2010 (phase 3).

\begin{tabular}{|c|c|c|c|c|c|c|}
\hline & Total & $\begin{array}{l}\text { Number }(\%) \text { of patients } \\
\text { enrolled into pre-ART } \\
\text { care } \leq 90 \text { days }\end{array}$ & $\begin{array}{c}\text { Number }(\%) \text { of } \\
\text { patients in } \\
\text { WHO stage } 3 / 4^{\mathrm{a}}\end{array}$ & $\begin{array}{c}\text { Median CD4 } \\
\text { count in } \\
\text { cells } / \mathrm{mm}^{3} \text { (IQR) }\end{array}$ & $\begin{array}{l}\text { Number }(\%) \text { of } \\
\text { ART-eligible } \\
\text { patients }{ }^{c}\end{array}$ & $\begin{array}{c}\text { Number }(\%) \text { of eligible } \\
\text { patients that started } \\
\text { ART } \leq 90 \text { days }\end{array}$ \\
\hline Total & 635 & $232 / 635(36.5)$ & $43 / 217(19.8)$ & 384 (214-539) & $93 / 208(44.7)$ & 48/93 (51.6) \\
\hline \multicolumn{7}{|c|}{ Department, by phase } \\
\hline OPD phase 1 & 73 & $32 / 73(43.8)$ & $7 / 28(25.0)$ & $287(112-387)$ & $16 / 27(59.3)$ & $11 / 16(68.8)$ \\
\hline OPD phase 3 & 125 & $37 / 125$ (29.6) & 7/37 (18.9) & $312(134-563)$ & $19 / 35(54.3)$ & 10/19 (52.6) \\
\hline VCT phase 1 & 237 & $92 / 237(38.3)$ & $12 / 85(14.1)$ & $398(288-533)$ & $30 / 81(37.0)$ & $16 / 30(53.3)$ \\
\hline VCT phase 3 & 200 & $71 / 200(35.5)$ & $17 / 67(25.4)$ & $431(245-655)$ & $28 / 65(43.1)$ & $11 / 28(39.3)$ \\
\hline$P$-value ${ }^{d}$ & & 0.180 & 0.317 & 0.008 & 0.132 & 0.304 \\
\hline \multicolumn{7}{|l|}{ Study site } \\
\hline Muhoza & 255 & $60 / 255(23.5)$ & $17 / 60(28.3)$ & $391(260-560)$ & $28 / 60(46.7)$ & $22 / 28(78.6)$ \\
\hline Ruhengeri & 13 & $6 / 13(46.2)$ & $3 / 6(50.0)$ & $177(97-440)$ & $4 / 6(66.7)$ & $3 / 4(75.0)$ \\
\hline Kibagabaga & 90 & $35 / 90(38.9)$ & $1 / 27(3.7)$ & $444(262-568)$ & $8 / 27(29.6)$ & $8 / 8(100.0)$ \\
\hline Kinyinya & 92 & $38 / 92(41.3)$ & $9 / 37(24.3)$ & $367(276-702)$ & $15 / 31(48.4)$ & $5 / 15(33.3)$ \\
\hline Kimironko & 158 & 78/158 (49.4) & 10/72 (13.9) & 358 (154-533) & $32 / 69(46.4)$ & $5 / 32(15.6)$ \\
\hline Rwaza & 27 & $15 / 27(55.6)$ & $3 / 15(20.0)$ & $369(215-408)$ & $6 / 15(40.0)$ & $5 / 6(83.3)$ \\
\hline$P$-value ${ }^{d}$ & & $<0.001$ & 0.017 & 0.306 & 0.537 & $<0.001$ \\
\hline \multicolumn{7}{|l|}{ Sex } \\
\hline Male & 243 & $92 / 243$ (37.9) & $18 / 86(20.9)$ & 311 (154-484) & 45/82 (54.9) & $27 / 46$ (58.7) \\
\hline Female & 392 & 140/392 (35.7) & 25/131 (19.1) & $422(269-605)$ & 48/126 (38.1) & 21/47 (44.7) \\
\hline$P$-value ${ }^{d}$ & & 0.585 & 0.739 & 0.003 & 0.017 & 0.176 \\
\hline \multicolumn{7}{|l|}{ Age group } \\
\hline $15-24$ years & 160 & $58 / 160(36.3)$ & 9/55 (16.4) & $487(288-660)$ & $18 / 53(34.0)$ & $7 / 18(38.9)$ \\
\hline $25-34$ years & 254 & $92 / 254(36.2)$ & $14 / 84(16.7)$ & $385(222-582)$ & $36 / 81(44.4)$ & $18 / 36(50.0)$ \\
\hline $35-44$ years & 122 & $44 / 122(36.1)$ & $10 / 42(23.8)$ & 317 (109-435) & $22 / 39(56.4)$ & $10 / 22(45.5)$ \\
\hline$\geq 45$ years & 90 & $38 / 90(42.2)$ & $10 / 36(27.8)$ & $360(215-453)$ & $17 / 35(48.6)$ & $13 / 17$ (76.5) \\
\hline$P$-value ${ }^{d}$ & & 0.753 & 0.415 & 0.011 & 0.183 & 0.125 \\
\hline
\end{tabular}


Those aged < 15 were excluded from the analyses. ART antiretroviral treatment; HIV Human immunodeficiency virus; IQR interquartile range; OPD Outpatient department; VCT Voluntary counselling and testing; WHO World Health Organization.

a. WHO stage was available for $217 / 232$.

b. CD4 count results were available for $218 / 232$.

c. ART eligibility was based on CD4 count (CD4<350 cells $/ \mathrm{mm}^{3}$ ) and WHO stage (stage 4), which were available for 208/232 patients

d. The $P$-values are based on Chi-squared test, Fisher's exact test or Kruskal-Wallis test, as appropriate. 
Table 2. Factors associated with non-enrolment among adult HIV patients diagnosed in VCT or OPD department of six Rwanda health facilities, March-May 2009 (phase 1) and December 2009February 2010 (phase 3); univariable and multivariable logistic regression.

\begin{tabular}{|c|c|c|c|c|c|}
\hline & $\mathrm{n} / \mathrm{N}(\%)$ & OR $(95 \% \mathrm{Cl})$ & $P$-value & aOR $(95 \% \mathrm{Cl})$ & $P$-value \\
\hline Total & $403 / 635$ (63.5) & & & & \\
\hline Phase & & & 0.177 & & 0.061 \\
\hline OPD phase 1 & 41/73 (56.2) & 1 & & 1 & \\
\hline OPD phase 3 & $88 / 125$ (70.4) & $1.9(1.0-3.4)$ & & $2.0(1.0-4.2)$ & \\
\hline VCT phase 1 & $145 / 237(61.2)$ & $1.2(0.7-2.1)$ & & $1.1(0.6-2.1)$ & \\
\hline VCT phase 3 & $129 / 200(64.5)$ & $1.4(0.8-2.4)$ & & $1.3(0.6-2.5)$ & \\
\hline Site & & & $<0.001$ & & $<0.001$ \\
\hline Muhoza & $195 / 255(76.5)$ & 1 & & 1 & \\
\hline Ruhengeri & 7/13 (53.9) & $0.4(0.1-1.1)$ & & $0.3(0.1-0.9)$ & \\
\hline Kibagabaga & 55/90 (61.1) & $0.5(0.3-0.8)$ & & $0.5(0.3-0.8)$ & \\
\hline Kinyinya & 54/92 (58.7) & $0.4(0.3-0.7)$ & & $0.4(0.2-0.7)$ & \\
\hline Kimironko & $80 / 158(50.6)$ & $0.3(0.2-0.5)$ & & $0.3(0.2-0.4)$ & \\
\hline Rwaza & $12 / 27(44.4)$ & $0.2(0.1-0.6)$ & & $0.3(0.1-0.7)$ & \\
\hline Sex & & & 0.586 & & 0.813 \\
\hline Female & 252/392 (64.3) & 1 & & 1 & \\
\hline Male & $151 / 243(62.1)$ & $0.9(0.7-1.3)$ & & $1.0(0.7-1.5)$ & \\
\hline Age & & & 0.756 & & 0.678 \\
\hline $15-24$ years & $102 / 160(63.8)$ & $1.3(0.7-2.3)$ & & $1.3(0.7-2.3)$ & \\
\hline 25-34 years & $162 / 254(63.8)$ & $1.3(0.8-2.1)$ & & $1.3(0.8-2.2)$ & \\
\hline $35-44$ years & $78 / 122$ (63.9) & $1.3(0.7-2.3)$ & & $1.4(0.8-2.6)$ & \\
\hline$\geq 45$ years & $52 / 90$ (57.8) & 1 & & 1 & \\
\hline
\end{tabular}


Those aged $<15$ years were excluded from the analyses. aOR adjusted odds ratio; HIV Human Immunodefiency Virus; OPD Outpatient department; VCT Voluntary counselling and testing; OR odds ratio; $95 \% \mathrm{Cl} 95 \%$ confidence interval. 
Table 3. Characteristics of 60 survey respondents who were not enrolled into pre-ART care in phase 3 of the study, their enrolment status at the time of the survey and reason(s) for non-enrolment, Rwanda, August 2010.

\begin{tabular}{|c|c|c|c|c|}
\hline & $\begin{array}{l}\text { All patients } \\
N=60\end{array}$ & $\begin{array}{c}\text { VCT-patients } \\
\mathbf{N}=\mathbf{3 4}\end{array}$ & $\begin{array}{c}\text { Out-patients } \\
N=26\end{array}$ & P value $^{\mathrm{a}}$ \\
\hline Median age (IQR) & $32(25-40)$ & $30(25-40)$ & $37(25-45)$ & 0.379 \\
\hline Sex & $\mathbf{N}(\%)$ & $\mathrm{N}(\%)$ & $\mathbf{N}(\%)$ & 0.362 \\
\hline Male & $26(43)$ & $13(38)$ & $13(50)$ & \\
\hline Female & $34(57)$ & $21(62)$ & $13(50)$ & \\
\hline Education & & & & 0.609 \\
\hline None & $10(17)$ & $5(15)$ & $5(19)$ & \\
\hline Primary & $39(65)$ & $24(71)$ & $15(58)$ & \\
\hline Secondary & $10(17)$ & $5(15)$ & $5(19)$ & \\
\hline Vocational training & $1(2)$ & $0(0)$ & $1(4)$ & \\
\hline Site & & & & $<0.001$ \\
\hline Muhoza & $27(45)$ & $20(59)$ & $7(27)$ & \\
\hline Ruhengeri & $5(8)$ & $0(0)$ & $5(19)$ & \\
\hline Kibagabaga & $5(8)$ & $0(0)$ & $5(19)$ & \\
\hline Kinyinya & $10(17)$ & $8(24)$ & $2(8)$ & \\
\hline Kimironko & $9(15)$ & $4(12)$ & $5(19)$ & \\
\hline Rwaza & $4(7)$ & $2(6)$ & $2(8)$ & \\
\hline Enrolled into pre-ART care at time of survey & & & & 0.644 \\
\hline Yes, before they took the HIV (re)test in phase 3 & $14(23)$ & $10(29)$ & $4(15)$ & \\
\hline Yes, at a different health facility & $10(17)$ & $5(15)$ & $5(19)$ & \\
\hline Yes, at the same health facility & $2(3)$ & $1(3)$ & $1(4)$ & \\
\hline No & $34(57)$ & $18(53)$ & $16(62)$ & \\
\hline Reason(s) for not enrolling into pre-ART care ${ }^{b}$ & $\mathrm{~N}=34$ & $\mathrm{~N}=18$ & $\mathrm{~N}=16$ & 0.485 \\
\hline Due to problems with the service at the health facility & $8(24)$ & $6(33)$ & $2(13)$ & \\
\hline Fear of the consequences of disclosing HIV status & $8(24)$ & $2(11)$ & $6(38)$ & \\
\hline
\end{tabular}


Difficulties accepting or mistrusting the test result Negative HIV test at different health facility

No time to come back to the clinic

Feeling healthy, do not see the need

Believe that prayers can cure HIV

Not seeing the benefit of taking ART

Other $^{\mathrm{c}}$

$\begin{array}{ccc}7(21) & 4(22) & 3(19) \\ 5(15) & 4(22) & 1(6) \\ 4(12) & 1(6) & 3(19) \\ 4(12) & 2(11) & 2(13) \\ 3(9) & 2(11) & 1(6) \\ 3(9) & 2(11) & 1(6) \\ 4(12) & 3(17) & 1(6)\end{array}$

ART antiretroviral treatment; HIV Human immunodeficiency virus; IQR interquartile range; VCT Voluntary counselling and testing.

a. The $P$-values are based on Chi-squared test, Fisher's exact test or Kruskal-Wallis test, as appropriate.

b. More reasons per person could be given

c. The other 4 reasons given were: due to a misunderstanding with the husband; lacking the willingness; lost health insurance card; too old to act upon the problem. 